The interaction of $\mathrm{P}$ by $\mathrm{S}$ was found to be highly significant. indicating that the effects of Ss differ at different sizes. This finding is not surprising. since people are known to vary in their abilities to see objects placed some distance away. It is interesting to note, as a result of a Duncan test. that for a particular $S$ there is also a significant difference in correct recognition scores when the visual system is presented with different sizes.

\section{REFERENCES}

Bledsoe, W. W., \& Browning, I. Pattern recognition and reading by machine. Proceedings of the Eastern Joint Computer Conference, 1959, 16, 225-232.

Campbell, F. W., \& Maffei, L. Electrophysiological evidence for the existence of orientation and size detectors in the human visual system. Journal of Physiology, 1970, 207, 635-652.

Dodwell, P. C. Visual pattern recognition. New York: Holt, Rinehart \& Winston, 1971.

Leibowitz, H. Some observations and theory on the variation of visual acuity with the orientation of the test object. Journal of the Optical Society of America, 1953,43,902-905.

Maffei, L., \& Campbell, F. W. Neurophysiological localization of the vertical and horizontal visual coordinates in man. Science, 1970, 167, 386-387.

Marzocco, F. N. Computer recognition of handwritten first names. IEEE Transactions on Electronic Computers, 1965. 210-217.

Mayzner, $M$. S. The research potential of a computer-based cathode-ray tube display system. Behavior Research Methods \& Instrumentation, 1968, 1, 41-43.

Mayzner, M. S. Visual information processing of alphabetic inputs. Psychonomic Monograph Supplements, 1972, 4(13, Whole No. 61), 239-243.

Mayzner, M S Tresselt, M. E. \& Helfer, M. S, A research strategy for studying for certain effects of very fast sequential input rates on the visual system. Psychonomic Monograph Supplements, 1967, 2(7, Whole No. 23), 91-108.

Sutherland, N. S. Visual discrimination of shape by octopus. British Journal of Psychology, 1957, 48, 55-70.

Sutherland, N. S. Cat's ability to discriminate oblique rectangles. Science, 1963a, 139, 209-210.

Sutherland, N. S. Shape discrimination and receptive fields. Nature, $1963 \mathrm{~b}, 197,118-122$.

Tou, J. T., \& Gonzalez, R. C. Automatic recognition of handwritten characters via feature extraction and multi-level decision. International Journal of Computer \& Information Sciences, 1972, 1, 43-66.

Uhr, L., \& Vossler, C. Pattern recognition program that generates, evaluates, and adjusts its own operators. In E. A. Feigenbaum and J. Feldman (Eds.), Computers and thought. New York: McGraw-Hill, 1963. Pp. 251-268.

Wade, N. J. Orientation effects on line afterimages. Perception \& Psychoph ysics, 1972, 12, 409-416.

1. 0 msec means no display.

\section{NOTE}

(Received for publication May 17, 1973.)

\title{
Instrumental and contingent saccharin-licking in rats: Response deprivation and reinforcement*
}

\section{JAMES ALLISON and WILLIAM TIMBERLAKE Indiana L'niversity. Bloomington. Ind. 47401}

It has been suggested that an instrumental response

*The research was supported in part by U.S. Public Health Service Grant MH-11470 to James Allison. will increase above its baseline if and only if the contingency schedule deprives the $S$ of the contingent response. Several experiments are reported in support of this contention. The principal finding was that instrumental licking of a $.4 \%$ saccharin solution was increased above its baseline by the contingent 
opportunity to lick a less preferred saccharin solution if the contingency schedule satisfied the response deprivation condition, but not otherwise.

Most reinforcement theories would agree that among thirsty rats. water-licking should reinforce instrumental wheel-running. It is a readily elicited consummatory response (Sheffield. 1966) in the approach category (Glickman \& Schiff. 1967) which ought to reduce drive (Hull, 1943) and strong thirst stimuli (Miller. 1951), and prevent counterconditioning (Guthrie, 1935). It has a higher operant probability than running (Premack. 1959, 1962). The rat seems sufficiently prepared (Seligman, 1970) to learn an association between running and water-licking. because contingent water-licking has often been found to increase instrumental running (Premack, 1962). Nevertheless, Premack (1965) reported that running does not increase if the contingency schedule does not deprive the $\mathrm{S}$ of the contingent water-licking response.

In this particular context, response deprivation is defined in terms of the total amount of running $\left(\mathrm{O}_{\mathrm{i}}\right)$ and the total amount of licking $\left(\mathrm{O}_{c}\right)$ performed during an operant baseline session in which the rat has free access to the running wheel and the drinking tube. In the contingency session, which is otherwise identical to the baseline session, the rat must run for access to the tube, and the parameters of the contingency schedule determine how much licking can be obtained for a particular amount of running. The contingency schedule is said to deprive the rat of licking when the following is true: if the rat performs only the baseline amount, $\mathrm{O}_{\mathrm{i}}$. of the instrumental running response, it will necessarily perform less than the baseline amount, $\mathrm{O}_{c}$, of the contingent licking response.

For example, consider a fixed-ratio schedule which requires $I$ units (commensurable with $\mathrm{O}_{\mathrm{i}}$ ) of running for access to $\mathrm{C}$ units (commensurable with $\mathrm{O}_{c}$ ) of licking. Suppose that $I$ is less than $O_{i}$, and $C$ is less than $O_{c}$. The contingency schedule deprives the rat of the contingent response if $(\mathrm{I} / \mathrm{C})>\left(\mathrm{O}_{\mathrm{i}} / \mathrm{O}_{\mathrm{c}}\right)$. Each time the rat performs I and then $\mathrm{C}$, it performs a greater proportion of $\mathrm{O}_{\mathrm{i}}$ than of $\mathrm{O}_{c}$. It follows that if the rat performs only $\mathrm{O}_{i}$ of the instrumental running response, it will hecessarily perform less than $\mathrm{O}_{c}$ of the contingent licking response. To approach $\mathrm{O}_{c}$ more closely, the rat must perform more than the baseline amount of running. The contingency schedule does not deprive the rat of the contingent licking response if $(\mathrm{I} / \mathrm{C}) \leqslant\left(\mathrm{O}_{\mathrm{i}} / \mathrm{O}_{\mathrm{c}}\right)$, because the rat can then approach $\mathrm{O}_{c}$ without performing more than the baseline amount of running.

When Premack (1965) first called attention to the response deprivation condition, he suggested that response deprivation was necessary for an increase in instrumental responding. Eisenberger, Karpman, \& Trattner (1967) attributed even more importance to the response deprivation condition by suggesting that it was not merely necessary. but sufficient. One of the most striking implications of their position is that a contingency schedule which satisfies the response deprivation condition will increase instrumental responding even if the contingent response has a lower operant probability than the instrumental response. Eisenberger et al (1967) reported a confirmation of this implication in a series of experiments on manipulatory behavior in humans. Because of its theoretical importance, we attempted to determine whether their finding could be generalized to consummatory behavior in rats.

All of the experiments reported here employed adult male albino rats, experimentally naive, given continuous access to food and water in the home cage. The test chamber was a standard operant conditioning box. Metal licking tubes were accessible through two holes drilled in a side wall, and access to each tube was controlled automatically by means of a motor-driven shutter attached to the outside wall of the box. Licking was monitored by solid-state drinkometer circuits grounded to the grid floor. All baseline and contingency sessions were $10 \mathrm{~min}$ long. In some experiments, we recorded the number of licks, and in others, the time spent licking at each tube. Time was cumulated by .1-sec clocks, which started with the beginning of each burst of licks and stopped at the end of each burst. The end of a burst was defined as an interlick interval greater than $250 \mathrm{msec}$ (Allison \& Castellan, 1970).

In the first experiment, one tube contained $.4 \%$ saccharin solution, and the other, $3 \%$ saccharin solution. The rats first received 18 baseline sessions, one per day, with both tubes freely available. The baselines, defined in terms of the mean of the last two sessions, showed that each of the 11 rats spent more time licking the $.4 \%$ tube than the $.3 \%$ tube. The group means were 269.9 and $39.5 \mathrm{sec}$, respectively. This baseline phase was followed by seven contingency sessions with $.4 \%$ licking as the instrumental response and $.3 \%$ licking as the contingent response. Each time the rat licked the $.4 \%$ tube for a total of $80 \mathrm{sec}$, the $.4 \%$ hole was closed and the $.3 \%$ hole opened simultaneously for $10 \mathrm{sec}$ $(\mathrm{I}=80 \mathrm{sec}, \mathrm{C}=10 \mathrm{sec})$. At the end of each 10 -sec access period. the $.3 \%$ hole was closed and the $.4 \%$ hole reopened. This contingency schedule deprived the Ss of $.3 \%$ licking, as $(80 / 10)>(269.9 / 39.5)$. If the average $\mathrm{S}$ were to approach $39.5 \mathrm{sec}$ of $.3 \%$ licking, it would have to lick the $.4 \%$ tube for considerably more than $269.9 \mathrm{sec}$.

Instrumental $.4 \%$ licking showed a significant increase across the seven contingency sessions $(F=2.43$, $\mathrm{df}=6 / 60 . \mathrm{p}<.05)$. The value obtained in the final session, $322.4 \mathrm{sec}$, was significantly higher than the baseline value of $269.9 \mathrm{sec}(\mathrm{t}=2.94, \mathrm{df}=10, \mathrm{p}<.02$; all $t$ tests reported here are two-tailed). Time spent licking the $.3 \%$ tube also increased across sessions $(F=3.74$, $\mathrm{df}=6 / 60, \mathrm{p}<.01)$. After the contingency phase. baselines were remeasured in another session with both 
Table 1

Time Spent Licking $.4 \%$ and $.3 \%$ Saccharin: Experiment 1

\begin{tabular}{|c|c|c|c|c|c|c|c|c|c|c|}
\hline \multirow[b]{2}{*}{ Response } & \multicolumn{2}{|c|}{$\begin{array}{c}\text { Precontingency } \\
\text { Baseline } \\
\end{array}$} & \multicolumn{7}{|c|}{ Contingency } & \multirow{2}{*}{$\begin{array}{l}\text { Postcon- } \\
\text { tingency } \\
\text { Baseline }\end{array}$} \\
\hline & 17 & 18 & 1 & 2 & 3 & 4 & 5 & 6 & 7 & \\
\hline $.4 \%$ & 270.3 & 269.5 & 263.6 & 271.9 & 284.8 & 273.3 & 285.0 & 325.9 & 322.4 & 284.6 \\
\hline $.3 \%$ & 41.5 & 37.5 & 0.4 & 1.6 & 5.5 & 5.5 & 7.6 & 6.0 & 6.6 & 42.1 \\
\hline
\end{tabular}

Table 2

Number of Licks at $.4 \%$ and $.1 \%$ Saccharin: Experiment 2

\begin{tabular}{|c|c|c|c|c|c|c|}
\hline \multirow[b]{2}{*}{ Response } & \multirow[b]{2}{*}{ Baseline } & \multicolumn{4}{|c|}{$\begin{array}{c}\text { Reciprocal Contingency Schedule } \\
(.4 \% \text { Licks } / .1 \% \text { Licks })\end{array}$} & \multirow{2}{*}{$\begin{array}{l}\text { Combined } \\
\text { Schedules }\end{array}$} \\
\hline & & $100 / 10$ & $200 / 20$ & $300 / 30$ & $400 / 40$ & \\
\hline $.4 \%$ & 851 & 1015 & 1100 & 989 & 1187 & 1069 \\
\hline $.1 \%$ & 613 & 96 & 95 & 85 & 99 & 94 \\
\hline
\end{tabular}

tubes freely available. There was no significant difference between pre- and postcontingency baselines (ts $<1)$. The data are summarized in Table 1.

A second experiment with eight rats obtained similar results, using $.4 \%$ saccharin licking as the instrumental response and $.1 \%$ saccharin licking as the contingent response. This experiment used reciprocal contingency schedules (Allison, 1971). in which the S must perform I units of the instrumental response for access to the contingent response, and must then perform $\mathrm{C}$ units of the contingent response to regain access to the instrumental response. The baselines were 851 licks at the $.4 \%$ tube and 613 licks at the $.1 \%$ tube $(\mathrm{t}=2.54$, $\mathrm{df}=7, \mathrm{p}<.05)$. Each rat was tested with four contingency schedules in a Latin square design, four sessions per schedule. One schedule required that the rat make 100 licks at the $.4 \%$ tube for access to the $.1 \%$ tube and 10 licks at the $.1 \%$ tube for regained access to the $.4 \%$ tube $(\mathrm{I} / \mathrm{C}=100 / 10)$. The other three schedules employed the same $\mathrm{I} / \mathrm{C}$ ratio as the schedule just mentioned, but differing values of I and C: 200/20, $300 / 30$, and $400 / 40$. Each schedule deprived each $S$ of $.1 \%$ licking. These identical $\mathrm{I} / \mathrm{C}$ ratios produced statistically identical amounts of $.4 \%$ licking $(\mathrm{F}<1)$ and $.1 \%$ licking $(\mathrm{F}<1)$. The mean number of $.4 \%$ licks, calculated across the four schedules, was 1.069-significantly more than the baseline value of 851 $(t=2.48, d f=7 . p<.05)$. The results are summarized in Table 2 .

A third experiment discounted the possibility that $.4 \%$ licking increased not because of its role as an instrumental response, but because it had direct substitute value for the less preferred response. When both tubes were freely available, eight rats spent $273.2 \mathrm{sec}$ licking the $.4 \%$ tube and $2.3 \mathrm{sec}$ licking the $.1 \%$ tube. If $.4 \%$ licking has substitute value for $.1 \%$ licking, then $.4 \%$ licking should increase if the $.1 \%$ tube is withdrawn. In fact, the rats spent only $273.3 \mathrm{sec}$ licking the $.4 \%$ tube in baseline sessions which offered free access to $.4 \%$ saccharin but no access to $.1 \%$ saccharin $(\mathrm{t}<1)$.
The same eight rats were used in a follow-up experiment to determine whether $.4 \%$ licking would increase if the schedule did not deprive the rats of $.1 \%$ licking. The reciprocal contingency schedule involved $50 \mathrm{sec}$ of $.4 \%$ licking and $4 \mathrm{sec}$ of .1\% licking. It did not deprive the Ss of $.1 \%$ licking, as $(50 / 4)<(273.2 / 2.3)$, and it did not increase $.4 \%$ licking. The time spent licking the $.4 \%$ tube, averaged across eight homogeneous training sessions, was only $211.4 \mathrm{sec}-$ significantly less than the baseline value of $273.2 \mathrm{sec}(\mathrm{t}=2.98, \mathrm{df}=7$, $\mathrm{p}<.05)$.

These experiments support the conclusion that an instrumental response will increase above its baseline if and only if the contingency schedule deprives the $\mathrm{S}$ of the contingent response. The increase occurs even if the contingent response has a lower commensurable baseline than the instrumental response.

\section{REFERENCES}

Allison, J. Microbehavioral features of nutritive and nonnutritive drinking in rats. Journal of Comparative \& Physiological Psychology, 1971, 76, 408-417.

Allison, J., \& Castellan, N. J. Temporal characteristics of nutritive drinking in rats and humans. Journal of Comparative \& Physiological Psychology, 1970, 70, 116-125.

Eisenberger, R., Karpman, M., \& Trattner, J. What is the necessary and sufficient condition for reinforcement in the contingency situation? Journal of Experimental Psychology, 1967, 74, 342-350.

Glickman, S. E.. \& Schiff, B. B. A biological theory of reinforcement. Psychological Review, 1967, 74, 81-109.

Guthrie, E. R. The psychology of learning. New York: Harper \& Row, 1935.

Hull, C. L. Principles of behavior. New York: A ppleton-CenturyCrofts, 1943.

Miller, N. E. Learnable drives and rewards. In S. S. Stevens (Ed.), Handbook of experimental psychology. New York: Wiley, 1951.

Premack, D. Toward empirical behavioral laws: I. Positive reinforcement. Psychological Review, 1959, 66, 219-233.

Premack, D. Reversibility of the reinforcement relation. Science, $1962,136,255-257$

Premack, D. Reinforcement theory. In D. Levine (Ed.), Nebraska symposium on motivation. Lincoln: University of Nebraska Press, 1965.

Seligman, M. E. P. On the generality of the laws of learning. Psychological Review, 1970, 77, 406-418.

Sheffield. F. D. A drive induction theory of reinforcement. In $R$. N. Haber (Ed.), Current research in motivation. New York: Holt, Rinehart \& Winston. 1966.

(Received for publication June 18. 1973.) 